\title{
Reversal of Propylthiouracil Induced-Fetal Ascites in Monochorionic Twins
}

\author{
${ }^{[}$Emre EKMEKCI $^{\mathrm{a}}$, ${ }^{\circledR}$ Alev ESERCAN ${ }^{\mathrm{b}}$, ${ }^{\circ}$ Yusuf Cem KAPLAN ${ }^{c}$ \\ ${ }^{a}$ Clinic of Obstetrics and Gynecology, Maternal-Fetal Medicine Unit, Şanlıurfa Training and Research Hospital, Şanlıurfa, TURKEY \\ ${ }^{b}$ Clinic of Obstetrics and Gynecology, Şanlıurfa Training and Research Hospital, Şanlıurfa, TURKEY \\ ${ }^{\mathrm{c}}$ Department of Pharmacology, Division of Clinical Pharmacology and Toxicology, İzmir Kâtip Çelebi University Faculty of Medicine, İzmir, TURKEY
}

\begin{abstract}
There are various causes in the etiology of fetal ascites and non-immune hydrops fetalis. Pathogenesis of non-immune hydrops fetalis is incompletely understood. The etiology cannot be determined in yet a large part of cases. Here we reported an isolated fetal ascites case in both fetuses, in a monochorionic pregnancy during maternal propylthiouracil (PTU) use. Fetal goiter was detected in both fetuses and after maternal oral tri-iodothyronine treatment, ascites resolved and babies were delivered at $36^{\text {th }}$ week of pregnancy. Anti-thyroid drugs (ATDs) should be used carefully during pregnancy. Fetal hypothyroidism may be associated with fetal hyrdrops. Maternal oral tri-iodothyronine administration may treat fetal hypothyroidism.
\end{abstract}

Keywords: Hydrops fetalis; hypothyroidism, congenital, nongoitrous, 1; propylthiouracil

Isolated fetal ascites is associated with several disorders and cannot be considered as fetal hydrops if only one compartment is affected. However, it commonly progresses to fetal hydrops. Dysregulation at fetal vascular and interstitial fluid leads to abnormal fluid collection in intraabdominal cavity. Multiple factors like chromosomal disorders, intrauterine infections, fetal cardiac failure and structural disorders of various organs are among the etiology of fetal ascites and non-immune hydrops fetalis. ${ }^{1}$ We present a case of fetal ascites due to maternal exposure to propylthiouracil (PTU) in monochorionic twin pregnancy. Both fetuses had enlarged goiters and marked ascites that were resolved completely by maternal triiodothyronine (T3) therapy.

\section{CASE REPORT}

A 30-year-old woman, gravida 1 para 0 , was referred to our perinatal medicine unit at 27 weeks of gesta- tion due to isolated fetal ascites detected at both fetuses in a monochorionic twin pregnancy, during routine ultrasound scan. Ultrasound examination revealed a monochorionic twin pregnancy and severe ascites in both fetuses (Figure 1). A previous ultrasound scan at $21^{\text {st }}$ week of gestation did not reveal any abnormalities. Maternal anamnesis did not indicate any notable condition. Complications due to monochorionicity were taken into account primarily and the patient underwent cordocentesis. Fetal hemoglobin levels were in normal limits, 12.5 and $13.1 \mathrm{~g} / \mathrm{dL}$ respectively. Direct Coombs was negative in both fetal blood samplings. Fetal karyotypes were both normal. Intrauterine infection screening did not reveal any congenital infection. Indirect Coombs was negative in maternal blood. The patient was re-evaluated two weeks later at $29^{\text {th }}$ week of gestation. The ascites in both fetuses were increased significantly and polyhydramniosis was present in both fetuses in

\footnotetext{
Correspondence: Emre EKMEKCI

Clinic of Obstetrics and Gynecology, Maternal-Fetal Medicine Unit, Şanlıurfa Training and Research Hospital, Şanlıurfa, TURKEY

E-mail: dr.ekmekci@hotmail.com

Peer review under responsibility of Journal of Clinical Obstetrics \& Gynecology.

Received: 07 Nov $2020 \quad$ Accepted: 19 Jan $2021 \quad$ Available online: 08 Feb 2021 
addition to previous findings. Information regarding the previous use of PTU was obtained after a re-interview with the patient, which was previously not mentioned by her during the admission. She was started $50 \mathrm{mg}$ PTU daily, in the tenth week of her pregnancy by an internal medicine physician due to hyperthyroidism. After this information, our examination was focused on fetal thyroid glands, which were found to be enlarged during the ultrasound scan (Figure 2, Figure 3). PTU was immediately discontinued and the patient was consulted to clinical pharmacology unit regarding intrauterine treatment of fetal goiter. The first line approach, intraamniotic levothyroxine (T4) therapy, could not be performed because the parenteral form of the drug was not available on the domestic market. An alternative therapy, maternal oral T3 option was also recommended by the clinical pharmacologist due to its rapid transplacental passage and higher potency of T3 compared to T4. $25 \mu \mathrm{g}$ of T3 was started via per-oral route once daily in the first week and increased to twice daily (50 $\mu \mathrm{g} /$ day) in the second week. The patient was counseled about hyperthyroidism symptoms and warned about tachycardia. On follow-up, significant regression of ascites in both fetuses, as well as decrease in the goiter sizes, was observed. The ascites completely regressed at $35^{\text {th }}$ week of pregnancy. The patient delivered uneventfully at 36 weeks. Baby A weighed 2,545 g with Apgar 8/10; Baby B weighed 2,350 $\mathrm{g}$ also with Apgar 8/10. Both neonates' thyroid status were normal and both were non-goitrous. Informed consent was obtained from the patient about the publication of clinical data.

Statement of Ethics: This article complies with the guidelines for human studies and includes evidence that the research was conducted ethically in accordance with the World Medical Association Declaration of Helsinki.

\section{DISCUSSION}

Fetal hypothyroidism may be related with several factors such as fetal thyroid dysgenesis, dyshormonogenesis, hypothalamic-pituitary dysfunction, TSH receptor mutations and placental transmission of maternal auto-antibodies or anti-thyroid drugs (ATD). Fetal hypothyroidism is usually not diagnosed in utero

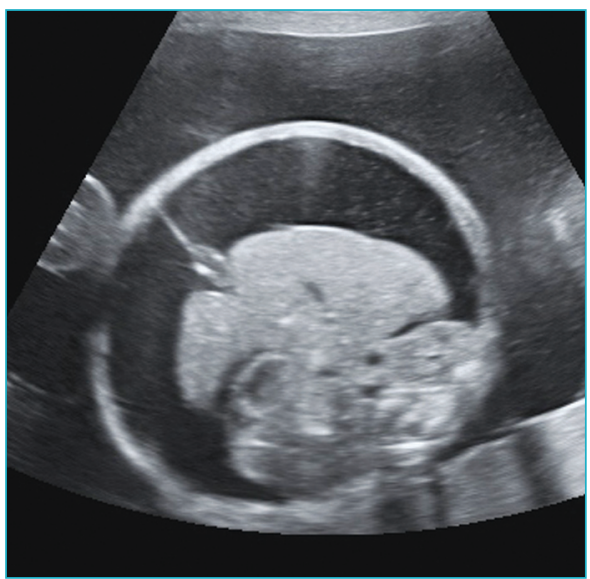

FIGURE 1: Isolated fetal ascites in one of the fetuses

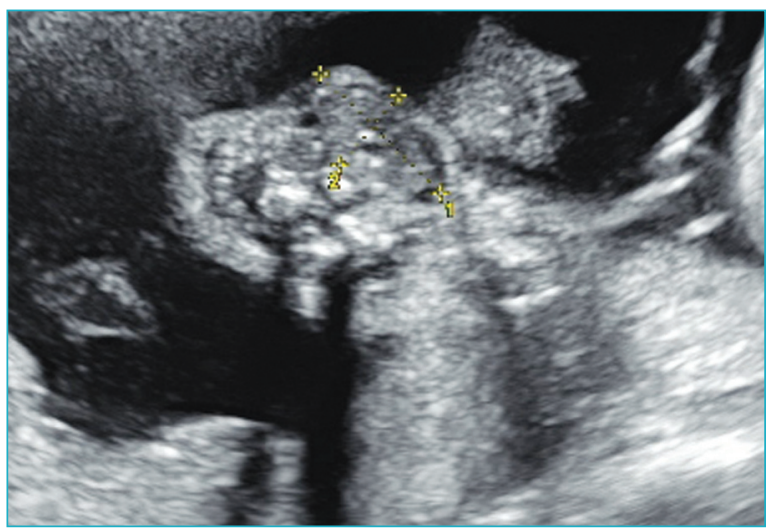

FIGURE 2: Enlarged thyroid gland on axial section.

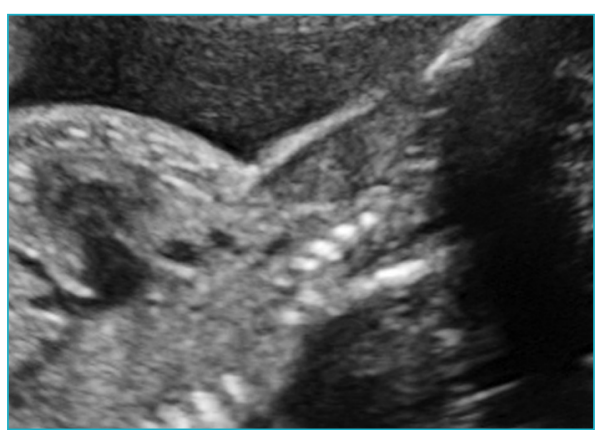

FIGURE 3: Enlarged thyroid gland on sagittal section.

because the transfer of $\mathrm{T} 4$ from the euthyroid mother provides the adequate levels of $\mathrm{T} 3$ required for the fetal development. ${ }^{2}$ However, if the mother is deficient for the thyroid hormones or fetal thyroid gland is severely inhibited, adequate hormone supply cannot be maintained by transplacental passage. ${ }^{3}$ Fetal goiter can cause dystocia during labor or may cause airway obstruction 
in the neonate. Hydrops secondary to fetal hypothyroidism is reported in limited cases in literature. ${ }^{1,45}$ According to our literature search, this is the first case of fetal hypothyroidism associated with fetal ascites in a twin pregnancy. Presentation of ascites in both fetuses in a monochorionic pregnancy directed us primarily to genetic disorders and intrauterine infections at the beginning since the patient did not give information about PTU use.

Successful treatment of fetal hypothyroidism in utero by intraamniotic injection of $\mathrm{T} 4$ has been described in the literature. ${ }^{6}$ However because of the unavailability of the parenteral form of the drug, we had to proceed with the maternal oral therapy with T3 which was selected particularly because of its higher potency compared to T4 and rapid transplacental passage. ${ }^{7}$ However, we had to be more cautious about the maternal thyrotoxicosis symptoms in this case. Fetal hydrops regressed quickly with the discontinuation of ATD and the initiation of treatment in both.

In conclusion, placental transfer of ATDs and possible fetal hypothyroidism should be kept in mind especially in patients under ATD medication. ATDs should be used when necessary with minimum dose to maintain maternal T4 levels in the upper normal ranges during pregnancy. Maternal treatment with T3 drugs seems to be a good alternative to intraamniotic
T4 therapy in selected cases when fetal hypothyroidism occurs.

\section{Acknowledgements}

We acknowledge and thank for the support of Clinical Pharmacology and Toxicology Unit of İzmir Kâtip Çelebi University Atatürk Training and Research Hospital (İzmir, Turkey) regarding their counseling about the management of patient.

\section{Source of Finance}

During this study, no financial or spiritual support was received neither from any pharmaceutical company that has a direct connection with the research subject, nor from a company that provides or produces medical instruments and materials which may negatively affect the evaluation process of this study.

\section{Conflict of Interest}

No conflicts of interest between the authors and / or family members of the scientific and medical committee members or members of the potential conflicts of interest, counseling, expertise, working conditions, share holding and similar situations in any firm.

\section{Authorship Contributions}

Idea/Concept: Emre Ekmekci; Control/Supervision: Emre Ekmekci, Alev Esercan; Data Collection and/or Processing: Emre Ekmekci, Yusuf Cem Kaplan; Analysis and/or Interpretation: Emre Ekmekci; Literature Review: Emre Ekmekci; Writing the Article: Emre Ekmekci, Alev Esercan; Critical Review: Yusuf Cem Kaplan, Alev Esercan.

\section{REFERENCES}

1. Bellini C, Hennekam RC. Non-immune hydrops fetalis: a short review of etiology and pathophysiology. Am J Med Genet A. 2012;158A(3):597-605. [Crossref] [PubMed]

2. Burrow GN, Fisher DA, Larsen PR. Maternal and fetal thyroid function. $\mathrm{N}$ Engl $\mathrm{J}$ Med. 1994;331(16):1072-8. [Crossref] [PubMed]

3. Dubuis JM, Glorieux J, Richer F, Deal CL, Dussault JH, Van Vliet G. Outcome of severe congenital hypothyroidism: closing the developmental gap with early high dose levothy- roxine treatment. J Clin Endocrinol Metab. 1996;81(1):222-7. [Crossref] [PubMed]

4. Pohl C, Szinnai G, Wellmann S. Non-immune hydrops fetalis and congenital hypothyroidism: coincidence or causality? Swiss Society of Neonatology. 2017. [Link]

5. Yuca SA, Cesur Y, Kırımi E, Sarı Ş, Kaya A, Doğan M. Congenital primary hypothyroidism associated with the rare form of nonimmune hydrops fetalis. Eastern J Med. 2010;15(1): 40-2. [Link]
6. Ribault V, Castanet M, Bertrand AM, Guibourdenche J, Vuillard E, Luton D, et al; French Fetal Goiter Study Group. Experience with intraamniotic thyroxine treatment in nonimmune fetal goitrous hypothyroidism in 12 cases. J Clin Endocrinol Metab. 2009;94(10):3731-9. [Crossref] [PubMed]

7. Namouz-Haddad S, Koren G. Fetal pharmacotherapy 4: fetal thyroid disorders. J Obstet Gynaecol Can. 2014;36(1):60-3. [Crossref] [PubMed] 